\title{
Exploration and Practice of the Teaching Model of the Course of Engineering Graphics under the Background of International Run-through Cultivation
}

\author{
Rui-can Hao* \\ School of Automotive Engineering \\ Beijing Polytechnic \\ Beijing, China \\ haoruican@163.com
}

\author{
Hua-gang Liu, Jin-ru Ma, Hui Yu \\ School of Automotive Engineering \\ Beijing Polytechnic \\ Beijing, China \\ Liuhuagang999@126.com
}

\begin{abstract}
Based on the analysis on the background of international run-through cultivation and the characteristics of the course of Engineering Graphics, the problems and shortcomings in the course teaching are found out. Aiming at the docking of domestic and foreign standards and the common problems in traditional teaching and learning, the advanced teaching modes and methods such as introducing foreign standards and case mapping into teaching, combining foreign systematic teaching method MOOC with online classroom application, computer software-assisted teaching and the application of AR technology are explored and practiced, so as to enable students to learn by practicing and enjoying themselves and achieve better teaching effect.
\end{abstract}

Keywords-International; Run-through; Engineering Graphics; Teaching

\section{INTRODUCTION}

\section{A. Background of International Run-through Cultivation}

With the implementation of the national internationalization strategy, more and more Chinese universities have established international colleges to cultivate international students jointly with foreign universities. Due to the different cultivation modes of universities at home and abroad, considering the future docking, the course of Engineering Graphics is facing many new challenges in the process of teaching implementation. At the same time, new requirements have been put forward for the teachers of the course of Engineering Graphics, which promotes teachers to continuously reform and innovate, explore new teaching methods and means, and enable students to master the course better and faster[1].

\section{B. Characteristics of the course of Engineering Graphics}

The course of Engineering Graphics takes shape construction and graphical expression as the core and image thinking as the mainline to cultivate students' basic qualities of engineering science, such as spatial imagination, image thinking, graphical expression and innovative configuration ability. It is an important part of engineering quality cultivation for students of science and engineering.

With the basic, graphical and engineering characteristics of engineering graphics technology, the course of Engineering Graphics cannot be replaced by other courses. The graphical and basic characteristics are embodied in projection theory, shape modeling method and expression technology, such as view, sectional view, axonometric mapping, etc. and drawing basis, such as bare-handed, ruler and computer drawing. The engineering characteristic is embodied in implementing relevant national standards and norms and learning to draw professional drawings, such as mechanical drawings, civil drawings, hydraulic drawings, etc. At the same time, the author undertakes the course of Engineering Graphics for students cultivated by domestic and international universities. In the course of teaching, the existing problems are explored and practiced.

\section{PROBLEMS IN TEACHING}

\section{A. Docking of Domestic and Foreign Standards:}

Due to the differences between German mechanical standards and domestic standards, it is difficult for students who have directly obtained German drawings to determine the content and standards. Therefore, we can help students complete international docking and transition by teaching and exercising specific topics in relevant national and industrial standards.

\section{B. Traditional Teaching and Learning Problems:}

The main purpose of engineering graphics is to cultivate students' ability to express and understand patterns and spatial thinking ability. However, due to students' inadequate spatial thinking ability, students generally feel that engineering graphics is difficult to learn. It is an important obstacle to the development of this course. It is abstract and difficult for students to understand. The single theoretical knowledge extracted from the machine and its parts lacks application 
examples and is difficult to understand. The students' drawing process is boring and not interesting.

\section{IMPROVEMENT MEASURES FOR TEACHING}

For the above problems, the teaching methods and means of the course are explored, practiced and improved.

\section{A. Introduce Foreign Standards and Case Mapping}

For example, more German standards and cases can be introduced for students in the German cultivation class, so that students can master the professional terminology exchange, corresponding standards, unit conversion and other knowledge, so as to lay a solid foundation for the smooth completion of international docking. At the same time, more manufacturing cases in corresponding countries can be introduced, so that students can study their design and mapping ideas and complete the mapping content, broaden their horizons, exercise the design and calculation ability, and improve the ability of further measurement and mapping. At the same time, by using the method of surveying and mapping foreign standard parts, students can learn and consolidate the knowledge of mapping in surveying and mapping practice and have a deeper understanding of foreign standards. For example, Fig. 1 is the marking of tool withdrawal groove (a) and the enlarged drawing of the groove (b). Through this kind of exercises, students could dimension parts skillfully. Fig.2 is a surveying and mapping case for students. This is the comprehensive application of knowledge. This case can help students master the standard requirements of Surveying and drawing more skillfully on the basis of understanding German-manufactured parts.

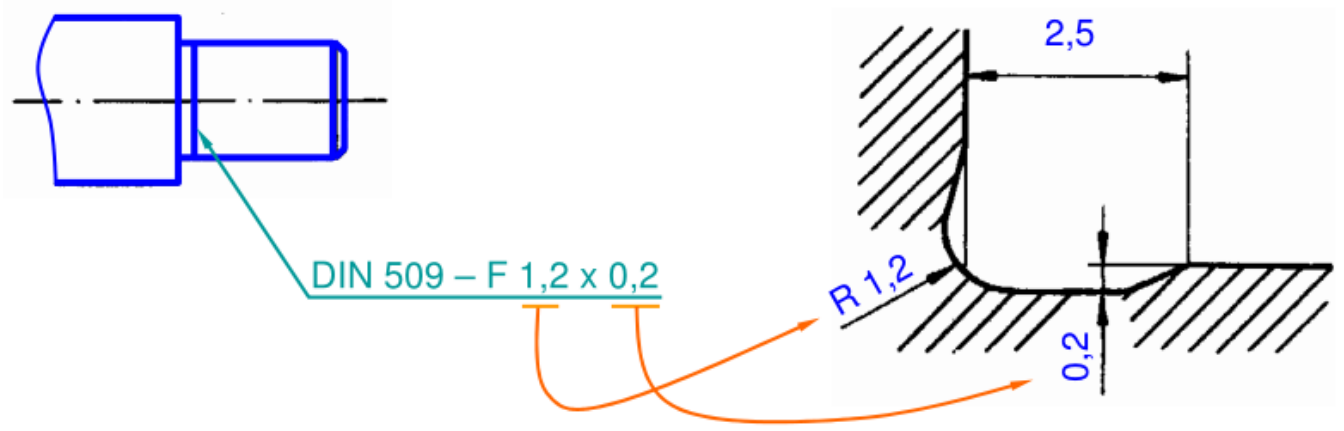

(a) Marking of tool withdrawal groove

(b) Enlarged drawing of the groove

Fig. 1. German dimensioning standard

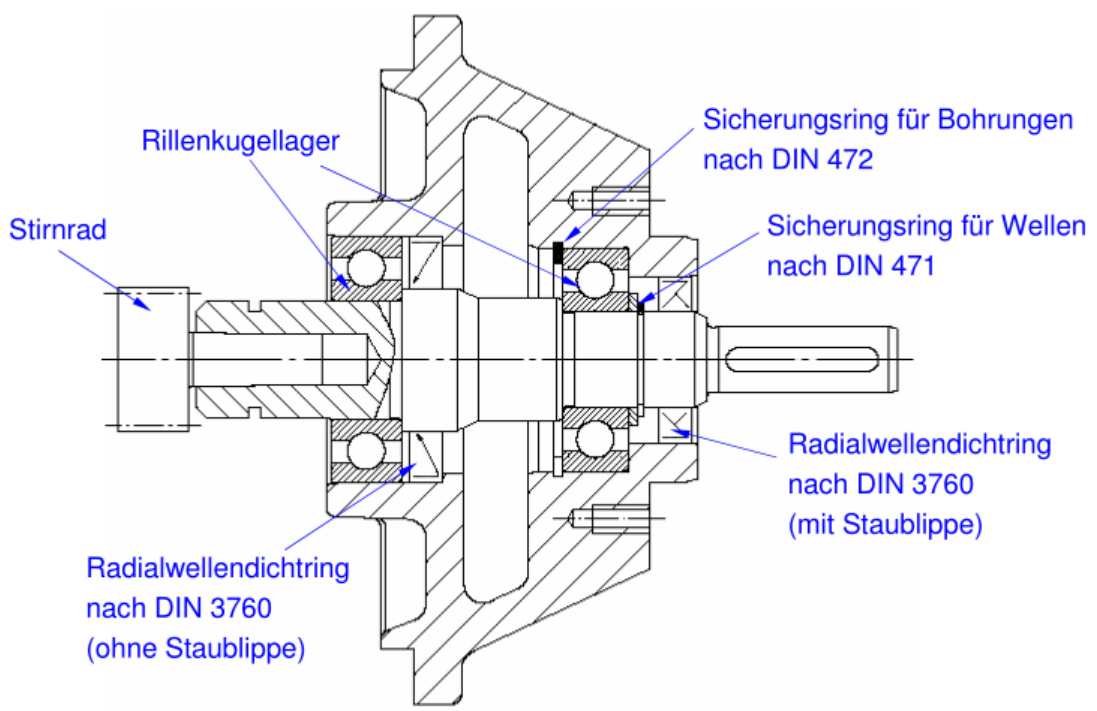

Fig. 2. A surveying and mapping case

\section{B. Combine with Foreign Systematic Teaching Methods}

In the German cultivation class, task-specific courses are jointly developed for the course of engineering graphics and other professional courses (such as mechanical principle, mechanical design and mechanical manufacturing technology) The knowledge of functional analysis, design calculation, drawing and process analysis of parts and components are 
concentrated in the completion of a task, so that students can personally experience the whole process of parts and components from design to finished products and achieve the teaching objectives. Task-driven method and thematic teaching are combined to enable students to master a series of professional knowledge and abilities.

\section{Combination of MOOC and Online Classroom [2-5]}

With the rapid development of modern network technology, MOOC (Massive Open Online Course) has gradually become the new favorite of "Internet + education", and is a revolution in the history of education. Online education provides a new mode of knowledge dissemination and learning, which will bring profound changes in educational concepts, educational system, teaching methods and talent cultivation process. Teaching reconstruction under MOOC background generally includes course planning, video recording, test design, course operation, etc. However, teaching content and video are not enough in the teaching process of a course. Teachers' answering of questions is an important part of students' learning process and an important part of traditional face-to-face courses which is different from network courses. Online courses can inherit the role of teachers in traditional courses, and communicate and interact with students at any time and anywhere. The specific interactive link can be periodically around fixed interactive topics for students, or questions about the classroom content can be answered through the platform. This not only increases students' interest in learning, but also answers questions efficiently.

\section{Computer Software-assisted Teaching[6-7]}

Students feel that the course is difficult to learn and they are unable to learn due to their poor spatial thinking ability. We can consider integrating computer software-assisted teaching in the teaching process of engineering graphics. For example, the application of three-dimensional modeling technology can effectively remedy the limitation of students' poor spatial thinking ability, and play an important role in improving students' learning efficiency and interest. Moreover, the National Educational Instruction Committee of Engineering Graphics has set "the ability to draw engineering drawings with drawing software and designing threedimensional models" as an important teaching task in this course, and lists the basic principles and operation techniques of computer modeling technology as the basis for teaching of engineering graphics. In the teaching process of engineering drawing, it is very important to choose the right time to integrate into the three-dimensional modeling software. Fig.3 and Fig.4 show two examples for students exercise using three-dimensional modeling software. Fig. 3 shows mechanical parts for producing. Students could improve Spatial imagination by practicing. Fig. 4 shows assembly drawing of lifting Jack. By the practices, students could improve assembling efficiency and splitting machine which could help students to understand two- dimensional drawing of the machine. Therefore, timely integration into the threedimensional design will not only help students learn the basic knowledge of the course of Engineering Graphics more easily, but also accelerate the development of students' spatial thinking ability. At the same time, it will also be helpful for students to understand the modeling idea and modeling process of the three-dimensional modeling design software.

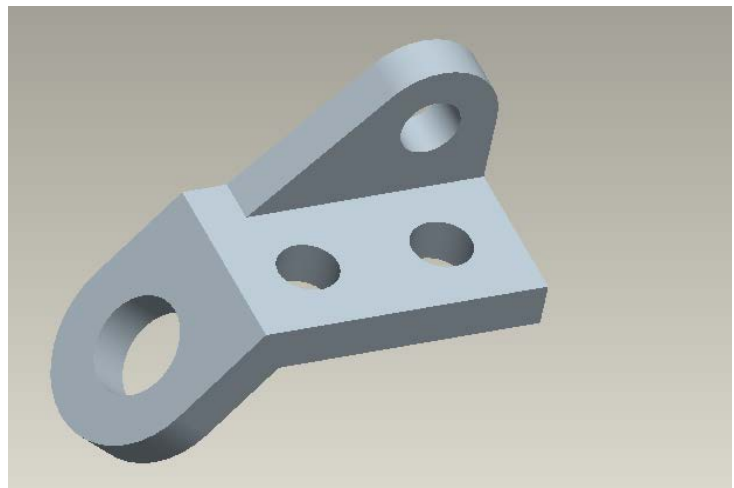

Fig. 3. Exercise example 1 for students

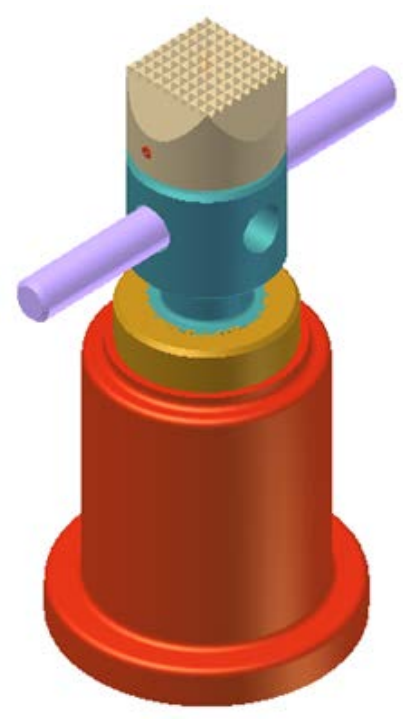

Fig. 4. Exercise example 2 for students

\section{E. Application of Augmented Reality Technology}

In order to stimulate students' interest in learning and innovative consciousness, advanced digital technology such as augmented reality (AR) technology can be used in teaching. AR technology is a new interactive technology originating from virtual reality (VR) technology. It superimposes the virtual information generated by the computer in real-time in real environment, thus creating visual experience and user experience with virtual and real fusion of [8]. A typical application of AR technology in engineering is virtual display of assembly process, which helps field operators to understand assembly process more accurately and quickly by displaying virtual process information on assembly site in real-time, thus improving assembly efficiency and quality [9]. The application of AR technology enables users to receive dual information of virtual and physical environment at the same time and obtain double feelings. Fig. 5 shows the effect of AR application. The interaction effect is the most intuitive. 
Therefore, in the teaching of Engineering Graphics, we can combine it with the scientific research of engineering, and use AR technology to show two-dimensional drawings in the three-dimensional model for real-time browsing. On the one hand, it can help to cultivate students' ability of spatial thinking. On the other hand, it can broaden students' horizons, and stimulate their interest in learning and innovative thinking, thus forming a benign interaction between scientific research and teaching and allowing teaching and learning to achieve twice the result with half the effort. This kind of AR technology is introduced into the teaching of graphics course, and a new teaching demonstration means is given. It is a teaching method worthy of learning and popularization [10].

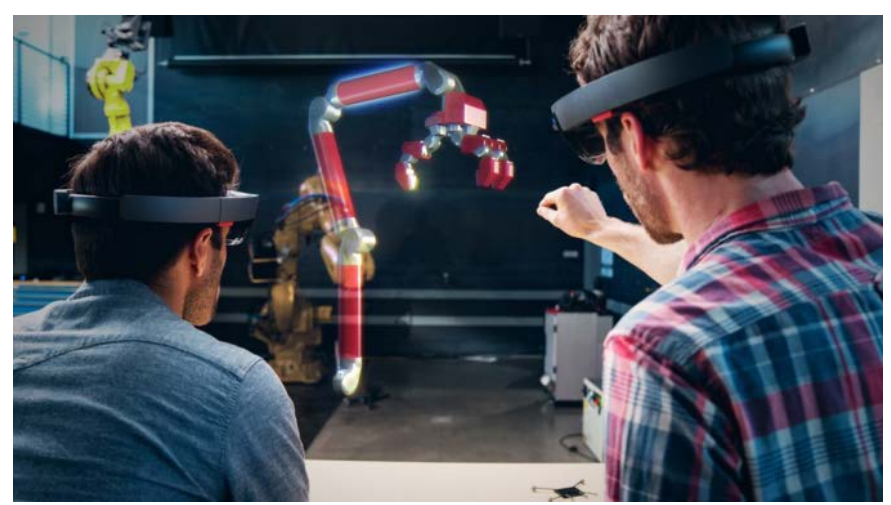

Fig. 5. Application of AR

\section{SUMMARY}

The advanced teaching modes and methods such as introducing foreign standards and case mapping into teaching, combining foreign systematic teaching method with online classroom application, computer software-assisted teaching and the application of AR technology are explored and practiced. Students have developed a strong interest in engineering graphics and corresponding practical courses, which has laid a solid foundation for the follow-up teaching of professional courses.

\section{ACKNOWLEDGMENT}

Thanks to the fund and support from the general program of Beijing Municipal Education Commission (NO.KM201910858005).

\section{REFERENCES}

[1] ZHAO Min-rong, JIANG Juan-na, WANG Bei, "Exploration and Practice of Teaching Model Reform of Engineering Graphics Course”, Educational Informatization Forum, vol 7, pp. 66-67, 2018 (In Chinese)

[2] KANG Lan, XI Wen-na, LIU Jiao, LI Ling, XU Li-qun, “Diversified Teaching Reforms and Practice of Engineering Graphics in Internet Plus Era”, EDUCATION TEACHING FORUM, vol 9, pp. 133-134, 2018 (In Chinese)

[3] Xu Dongmei and Chen Songping, “Application Research of Engineering Graphics Teaching Based on the Concept of Flipping Classroom", Science and Education Educational Journal (Electronic Edition), vol 30, pp. 73-75, 2018 (In Chinese)

[4] JIANG Shan, XU Jian: Construction and Commissioning of Engineering Graphics Online Course. Education Teaching Forum, 12, 102-103, 2018 (In Chinese)

[5] Zhou Liang, Xie Xihua, "Exploration on the Innovation of Engineering Graphics Teaching Model in the Internet Era”, University Education, vol 1, pp. 47-49, 2018(In Chinese)

[6] Le Tianming, Jiang Min, "Reform and Exploration of Engineering Graphics Teaching Oriented to Intelligent Manufacturing Technology”, University Education, vol 5, pp. 102-104, 2018 (In Chinese)

[7] Zhang Zongbo, Wang Min, Niu Wenjie, et al, "Exploration of Engineering Graphics Teaching Integrating with Three-dimensional Modeling Technology, ” Journal Of Higher Education, vol 21, pp. 76-78, 2018(In Chinese)

[8] Xing Guo-wang, "A Survey of Augmented Reality on Android", Electronic Science \& Technology, vol 1(2), pp. 206-211, 2014(In Chinese)

[9] HAKKARAINEN M, WOODWARD C, BILLINGHURST M, "Augmented assembly using a mobile phone”, IEEE/ACM International Symposium on Mixed and Augmented Reality, pp. 167-168, IEEE Press, New York 2008

[10] YU Yong, ZHAO Gang, LI Yachu, “Application of Augmented Reality Technology in Engineering Graphics Education, ” Journal of Graphics, vol 39(1), pp. 175-178, 2018 (In Chinese) 